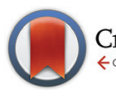

CrossMark \& click for updates

Cite this: Polym. Chem., 2015, 6 , 4984

Received 27th April 2015, Accepted 10th June 2015

DOI: $10.1039 / c 5 p y 00617 a$

www.rsc.org/polymers

\title{
RAFT dispersion polymerization: a method to tune the morphology of thymine-containing self-assemblies $\uparrow$
}

\author{
Yan Kang, Anaïs Pitto-Barry, Anna Maitland and Rachel K. O'Reilly* \\ The synthesis and self-assembly of thymine-containing polymers were performed using RAFT dispersion \\ polymerization. A combination of microscopy and scattering techniques was used to analyze the resultant \\ complex morphologies. The primary observation from this study is that the obtained aggregates induced \\ during the polymerization were well-defined despite the constituent copolymers possessing broad dis- \\ persities. Moreover, a variety of parameters, including the choice of polymerization solvent, the degree of \\ polymerization of both blocks and the presence of an adenine-containing mediator, were observed to \\ affect the resultant size and shape of the assembly.
}

\section{Introduction}

Heterogeneous polymerizations, including dispersion, emulsion, suspension, and precipitation polymerizations, are easily performed and widely used in industry. ${ }^{1}$ Recently the combination of heterogeneous polymerization with reversible-deactivation radical polymerization (RDRP) has become of great interest, given that this approach can combine the advantages of heterogeneous polymerization with the controlled nature of RDRP methods. ${ }^{2,3}$ RDRP techniques including reversible addition-fragmentation chain-transfer

(RAFT) polymerization, ${ }^{3-5}$ various forms of atom-transfer radical polymerization (ATRP), ${ }^{6,7}$ nitroxide-mediated polymerization (NMP), ${ }^{8,9}$ amongst other methods ${ }^{10-12}$ have been readily applied in this area. A number of these processes offer significant advantages in the design of well-defined nanoobjects through the synthesis of their corresponding block copolymers. ${ }^{13-18}$ For example, RAFT dispersion polymerization has been widely developed to prepare a solvent-insoluble polymer block from a solvent-soluble monomer in the presence of a solvent-soluble macromolecular chain transfer agent (macro-CTA). ${ }^{15,19-24}$ In most cases, by simply varying the polymerization conditions, a range of common morphologies (spheres, cylinders, vesicles) and a few novel structures (lumpy rod, ${ }^{25}$ framboidal morphology, ${ }^{26}$ concentric vesicle, ${ }^{27}$ and knot-like structure ${ }^{28}$ ) can be obtained. In addition, the resul-

Department of Chemistry, University of Warwick, Gibbet Hill Road, Coventry, CV4 7AL, UK. E-mail: Rachel.oreilly@warwick.ac.uk

$\dagger$ Electronic supplementary information (ESI) available: ${ }^{1} \mathrm{H}$ NMR spectra, SEC, DLS, SANS, SAXS, SLS data. See DOI: 10.1039/c5py00617a tant block copolymers are generally obtained with good blocking efficiencies and relatively low dispersities.

Recently we have demonstrated the synthesis of nucleobase-containing materials using RAFT dispersion polymerization. ${ }^{28}$ In our previous study, poly(methyl methacrylate) (PMMA) was used as the macro-CTA and only adenine-containing monomers or a mixture of adenine-containing monomers and thymine-containing monomers were used to chain extend the PMMA block. RAFT dispersion polymerizations were investigated in both chloroform and 1,4-dioxane. It was found that using these conditions polymers obtained were generally wellcontrolled in terms of molecular weight and molecular weight distribution. Moreover, it was also observed that the choice of polymerization solvent played a key role in the final morphologies achieved.

Thymine is one of the natural nucleobases in DNA and binds to adenine via complementary hydrogen bonding interactions to stabilize DNA and enable the formation of a double helix. Moreover, it is also well-known that thymine can form triple hydrogen bonds with diaminopyridine or its derivatives. $^{23,24}$ Based on these properties, thymine is commonly used for controlling polymer tacticity, ${ }^{29}$ templating polymerizations, ${ }^{30-32}$ facilitating molecular self-assembly and aggregation $^{33-36}$ and protecting active moieties. ${ }^{37}$ However, there are still few reports on the systematic study of the selfassembly of thymine-containing polymers of various lengths. ${ }^{33,38}$ Considering the advantages of RAFT dispersion polymerizations, we have applied this approach to readily prepare a variety of thymine-containing nanostructures. However, compared to our previous work on RAFT dispersion polymerization to prepare nucleobase-containing nanostructures, ${ }^{28}$ contrasting results in terms of morphology and 
molecular weight distributions of the resultant polymers have been observed. Indeed, in the pure thymine system the produced morphologies are more varied and better defined despite the fact that the resultant polymers are bimodal in most cases. This contradicts current thinking that narrow dispersity block copolymers are a prerequisite for the formation of well-defined assemblies. ${ }^{39}$ However, this study shows that well-defined nanoobjects can still be attained although the constituent block copolymers possess broad dispersities $\left(\oslash_{M}\right.$ often greater than 1.5). Indeed, the study of the solution behavior of polydisperse block amphiphiles is of growing scientific interest. ${ }^{40-48}$ It is known that block copolymers with broad dispersities affect the interfacial curvature, which allows structures with non-constant interfacial mean curvatures, but that are thermodynamically stabilized, to form (e.g., prolate-spheroid micelles, ${ }^{40}$ stabilized vesicles, ${ }^{43}$ and more complex structures $\left.{ }^{42,49}\right)$. In order to further extend this concept we have performed RAFT dispersion polymerizations of a thymine-containing monomer, which under varying conditions can undergo hydrogen-bonding to allow for more complex polymerization procedures. To explore this fully a range of polymerization conditions were explored and their effect on the resultant morphologies and polymers investigated. Such functional polymers, capable of intra- and intermolecular $\mathrm{H}$-bonding interactions are an interesting emerging class of new materials which enable access to novel morphologies and can provide an insight into the self-assembly process of such complex functional polymers.

\section{Experimental}

\section{Materials}

Methyl methacrylate (MMA) was bought from Aldrich and passed through a column of neutral alumina to remove the inhibitor. 2,2-Azo-bis(isobutyronitrile) (AIBN) was purchased from Molekula and recrystallized twice from methanol. The synthesis of 2-cyano-2-propyl dodecyl trithiocarbonate (CPDT) was based on a previous report. ${ }^{50}$ Thymine-functionalized monomer, 2-(2-(thymine-1-yl)acetoxyl) ethyl methacrylate (TMA), was synthesized according to our published method. ${ }^{51}$ Adenine-containing mediator, 9-hexyladenine, was synthesized according to a previous report. ${ }^{52}$ 1,4-Dioxane, chloroform $\left(\mathrm{CHCl}_{3}\right)$, and other solvents were used as received from Fisher Scientific. Deuterated solvents were bought from Apollo Scientific.

\section{Homopolymerization of TMA}

The typical procedure for the RAFT polymerization of TMA was as follows: TMA, CPDT (1 eq.) and AIBN (0.1 eq.) were dissolved in 1,4-dioxane. The mixture was degassed via 4 freezepump-thaw cycles, filled with nitrogen and then immersed into an oil bath at $60{ }^{\circ} \mathrm{C}$. The polymerization was quenched in a liquid nitrogen bath and exposing to air. The mixture was concentrated and precipitated into cold methanol. The polymer was washed with methanol several times and dried in a vacuum oven. The polymer was characterized by ${ }^{1} \mathrm{H}$ NMR spectroscopy and SEC (DMF eluent, PMMA standards).

\section{Polymerization of methyl methacrylate (MMA)}

The typical procedure of RAFT polymerizations of MMA was as follows: MMA, CPDT (1 eq.) and AIBN (0.1 eq.) were dissolved in toluene. The mixture was degassed via 4 freeze-pump-thaw cycles, filled with nitrogen and then immersed into an oil bath at $60{ }^{\circ} \mathrm{C}$. The polymerization was quenched by putting into a liquid nitrogen bath and exposing to air. The mixture was precipitated into cold methanol and filtered. The polymer was dissolved in THF and precipitated again. This precipitation procedure was repeated 3 times in total to remove unreacted monomer. The light yellow polymers were dried in a vacuum oven and characterized by ${ }^{1} \mathrm{H}$ NMR spectroscopy and SEC (DMF eluent, PMMA standards).

\section{Synthesis of block copolymers using PMMA as macro-CTA}

The typical procedure was as follows: PMMA (1 eq.), TMA (X), adenine mediator $(\mathrm{X})$ and AIBN (0.1 eq.) were dissolved in chloroform, 1,4-dioxane or mixtures of the two solvents. The mixtures were thoroughly degassed via 4 freeze-pump-thaw cycles, filled with nitrogen and then immersed into an oil bath at $60{ }^{\circ} \mathrm{C}$. The polymerizations were quenched by exposing to air and cooling down. The mixture was precipitated in methanol and washed with methanol several times. The polymers were dried in a vacuum oven and characterized by ${ }^{1} \mathrm{H}$ NMR spectroscopy and SEC (DMF eluent, PMMA standard). The DP of the block was varied by adding different amounts of TMA.

\section{Characterization}

${ }^{1} \mathrm{H}$ NMR spectra were recorded on a Bruker DPX-300 or DPX-400 spectrometer with DMSO- $d_{6}$ or deuterated chloroform $\left(\mathrm{CDCl}_{3}\right)$ as the solvent. The chemical shifts of protons were reported relative to tetramethylsilane at $\delta=0 \mathrm{ppm}$ or solvent residues $\left(\mathrm{CHCl}_{3}{ }^{1} \mathrm{H}\right.$ : $7.26 \mathrm{ppm}$; DMSO $\left.{ }^{1} \mathrm{H}: 2.50 \mathrm{ppm}\right)$.

Size exclusion chromatography (SEC) was performed in HPLC grade DMF containing $5 \mathrm{mM} \mathrm{NH}_{4} \mathrm{BF}_{4}$ at $50{ }^{\circ} \mathrm{C}$, with a flow rate of $1.0 \mathrm{~mL}$ per minute, on a set of two PLgel $5 \mu \mathrm{m}$ Mixed-D columns, plus one guard column. SEC data was analyzed with Cirrus GPC software calibrated using polymethyl methacrylate (PMMA) standards. The SEC was equipped with both refractive index (RI) and UV detectors.

Transmission electron microscopy (TEM) was performed on a JEOL 2000FX electron microscope at an acceleration voltage of $200 \mathrm{kV}$. All TEM samples were prepared on graphene oxide (GO)-coated carbon grids (Quantifoil R2/2) which allows high contrast images to be acquired without staining. ${ }^{53}$ Generally, a drop of sample $(20 \mu \mathrm{L})$ was deposited on a grid which was placed on a piece of filter paper and then left to air dry.

Hydrodynamic diameters $\left(D_{\mathrm{h}}\right)$ and size distributions of the self-assemblies were determined by dynamic light scattering (DLS). The DLS instrumentation consisted of a Malvern Zetasizer NanoS instrument operating at $25{ }^{\circ} \mathrm{C}$ with a $4 \mathrm{~mW} \mathrm{He-Ne}$ $633 \mathrm{~nm}$ laser module. Measurements were made at a detection angle of $173^{\circ}$ (back scattering), and Malvern DTS 6.20 software 
was used to analyze the data. The viscosity of the mixtures of $\mathrm{CHCl}_{3}$ and 1,4-dioxane is estimated by a simplified equation. ${ }^{54}$

$$
\ln \eta=X_{1} \ln \eta_{1}+X_{2} \ln \eta_{1}
$$

where $\eta$ is the viscosity of the solution, and $X_{1}, X_{2}, \eta_{1}, \eta_{2}$ are the mole fractions and viscosities of the two components in a binary mixture.

Static light scattering (SLS) measurements were performed using an ALV CGS3 $(\lambda=632 \mathrm{~nm})$ at $20^{\circ} \mathrm{C}$. The data was collected from $12^{\circ}$ up to $30^{\circ}$ with an interval of $2^{\circ}$ or $30^{\circ}$ up to $150^{\circ}$ with an interval of $10^{\circ}$ and calibrated with filtered toluene and filtered $\mathrm{CHCl}_{3}$ as backgrounds. The refractive index increment of the polymer in $\mathrm{CHCl}_{3}$ was measured to be $0.053 \mathrm{~mL} \mathrm{~g}^{-1}$.

Small-angle neutron scattering (SANS) experiments were recorded at the ISIS neutron beam facility, on the sans2d instrument at the Rutherford Appleton Laboratory, Oxford. Samples were measured at $20 \mathrm{mg} \mathrm{mL}{ }^{-1}$ in $\mathrm{CDCl}_{3}$, which provides high contrast in scattering length for the polymer. Smallangle X-ray scattering (SAXS) experiments were carried out on the SAXS-WAXS beamline at the Australian Synchrotron facility at a photon energy of $15 \mathrm{keV}$. The samples were prepared in 1,4-dioxane and were run using $1.5 \mathrm{~mm}$ diameter quartz capillaries. The measurements were collected at $25{ }^{\circ} \mathrm{C}$ with a sample to detector distance of $7.160 \mathrm{~m}$ to give a $q$ range of 0.0015 to $0.08 \AA^{-1}$, where $q$ is the scattering vector and is related to the scattering angle $(2 \theta)$ and the photon wavelength $(\lambda)$ by the following equation:

$$
q=\frac{4 \pi \sin (\theta)}{\lambda}
$$

All patterns were normalized to fixed transmitted flux using a quantitative beam stop detector. The scattering from the solvent was measured in the same location as sample collection and was subtracted for each measurement. The twodimensional SAXS images were converted into one-dimensional SAXS profiles $(I(q)$ versus $q$ ) by circular averaging, where $I(q)$ is the scattering intensity. ScatterBrain and NCNR Data Analysis IGOR Pro software were used to plot and analyze SAXS and SANS data. ${ }^{55}$ The scattering length density of the solvents and monomers were calculated using the "Scattering Length Density Calculator" provided by the NIST Center for Neutron Research. $^{56}$

\section{Results and discussion}

The homopolymerizations of TMA in chloroform and DMF were reported in our previous study. ${ }^{51}$ Although TMA could be polymerized in chloroform, due to the heterogeneous nature of the polymerization it was not well-controlled. ${ }^{51}$ However, poly(TMA) obtained using DMF as the polymerization solvent was well-defined in terms of molecular weight and molecular weight distribution. ${ }^{51}$ In this study, the homopolymerization of TMA in 1,4-dioxane was also performed. The solubility of PTMA in 1,4-dioxane was improved compared to that in chloroform, although some precipitation of the polymer still occurred as the polymerization proceeded, however, the molecular weight distribution of the resultant polymer was narrower (1.14 versus 1.86) and the resultant molecular weight was more controlled compared to polymerization in chloroform (polymer 1, Fig. S1 and Table S1†). These observations suggest that it is possible to perform RAFT dispersion polymerizations of TMA using 1,4dioxane as the solvent. Based on these observations 1,4dioxane was used a good solvent for the dispersion polymerization with a PMMA macro-CTA.

The synthetic route for the PMMA macro-CTA synthesis (2 and 3) is shown in Scheme 1. CPDT was used as the CTA as it is suitable for the polymerization of methacrylates and the polymerizations were stopped at relatively low conversion $<60 \%$ to ensure good end group fidelity. The DP of the PMMA macro-CTA was determined by ${ }^{1} \mathrm{H}$ NMR spectroscopy by comparing the integration of PMMA backbone signals with those of the CPDT end group. The resulting DPs of PMMA were ca. 70 (polymer 2) and 220 (polymer 3). SEC (DMF as eluent, PMMA standards) was used to further determine the molecular weight and the molecular weight distribution. In addition to the observed narrow molecular weight distributions, the molecular weights from SEC are consistent with the results from ${ }^{1} \mathrm{H}$ NMR spectroscopy. Furthermore, the RI SEC trace and UV SEC trace $(\lambda=309 \mathrm{~nm}$ from trithiocarbonate end group) overlap well, suggesting good end group fidelity (Fig. S2†).

RAFT dispersion polymerizations of TMA were performed at $60{ }^{\circ} \mathrm{C}$ using 2 or 3 as the macro-CTA and AIBN as the initiator. The conversions of the polymerizations were determined by ${ }^{1} \mathrm{H}$ NMR spectroscopy and the molecular weight and molecular weight distributions were analysed by SEC (DMF as eluent, PMMA as standards). The morphologies induced during the polymerizations were characterized by both light scattering

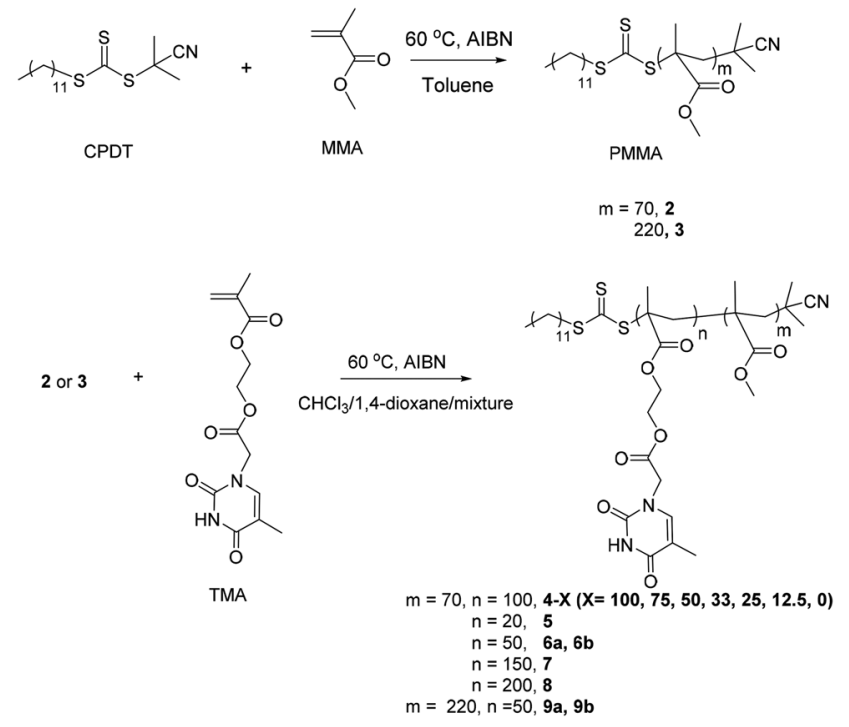

Scheme 1 Synthetic route for the macro-CTAs (PMMA, 2 and 3) and the thymine-containing diblock copolymers using RAFT dispersion polymerization (4-9). 
and microscopy analysis. To explore the polymerization parameters more fully and understand the dispersion polymerization procedure a range of conditions (including solvent quality, nucleobase block length, addition of a mediator) were utilized to prepare the block copolymers and nanostructures.

\section{Effect of solvent}

As observed in our previous study, solvent plays a key role in the RAFT dispersion polymerization of nucleobase-containing monomers ${ }^{28}{ }^{2}$ where different morphologies are observed using different solvents. In this study, chloroform, 1,4-dioxane, and mixtures of the two solvents at various ratios were utilized as the polymerization solvent to study the effect on the RAFT dispersion polymerization of TMA. The initial ratio of macro-CTA : TMA: AIBN was $1: 100: 0.1$ and PMMA with a DP of 70 was used as the macro-CTA, 2, (the polymers/polymerizations were named as $\mathbf{4 - \mathbf { X }}$; where $\mathbf{X}$ denotes the composition of chloroform in a solvent mixture), see Table S1. $\dagger$

Under these different solvent conditions a range of assembly morphologies were obtained for the targeted block copolymer $\mathrm{PMMA}_{70}-b$-PTMA 100 . When pure chloroform was used as the polymerization solvent, a bimodal molecular weight distribution was observed by SEC and only well-defined aggregates (ca. $200 \mathrm{~nm}$ ) were observed by light scattering (Table S1 4-100 and Fig. S3 $\dagger$ ). Examination of the reaction mixture by dry state TEM indicated that vesicles were formed during the dispersion polymerization (Fig. 1a, 4-100). To eliminate the possibility of imaging artefacts caused by imaging particles in the dry-state, SLS was also conducted on the sample to further determine the morphology (Fig. S3†). A Zimm analysis revealed that the P-ratio $\left(R_{g} / R_{\mathrm{h}}\right.$, ratio between radius of gyration and hydrodynamic radius) of the nanostructures was close to $1\left(R_{\mathrm{g}} / R_{\mathrm{h}}=\right.$ 1.17), indicating the formation of hollow structures. ${ }^{57,58}$ SANS was also conducted on a more concentrated sample $(20 \mathrm{mg}$ $\mathrm{mL}^{-1}$ ), which was obtained directly from the polymerization solution without dilution (Fig. S4†). The Guinier-Porod fit was firstly applied to confirm a spherical shape for these assemblies. ${ }^{59}$ Furthermore, the thickness of the vesicle membrane was determined from a plot of $q^{2} I(q)$ versus $q .{ }^{60}$ The first minimum of this plot $q$ corresponds to the first zero of the membrane factor given by:

$$
d=2 \pi / q
$$

where $d$ is the membrane thickness. Such a plot gave a thickness of $41 \mathrm{~nm}$ (Fig. S4 $\dagger$ ). To investigate the morphology of the assembly in more detail, the polycoreshell ratio model (from the NIST package) was also used. ${ }^{61}$ In this model, both core and shell are polydisperse and the core is considered as the solvent-filled lumen of the vesicles. From the fit, the thickness of the shell (the membrane in our study) is determined to be $38.3 \mathrm{~nm}$ and the radius of the core (the lumen in this study) is $70.0 \mathrm{~nm}$ with a dispersity of both the core and the shell of 0.18. The thickness of the membrane correlates well with the value determined using the $q^{2} I(q)$ versus $q$ plot. The total radius $(108.3 \mathrm{~nm})$ is also consistent with the results from DLS and TEM analysis. Moreover, the scattering length density
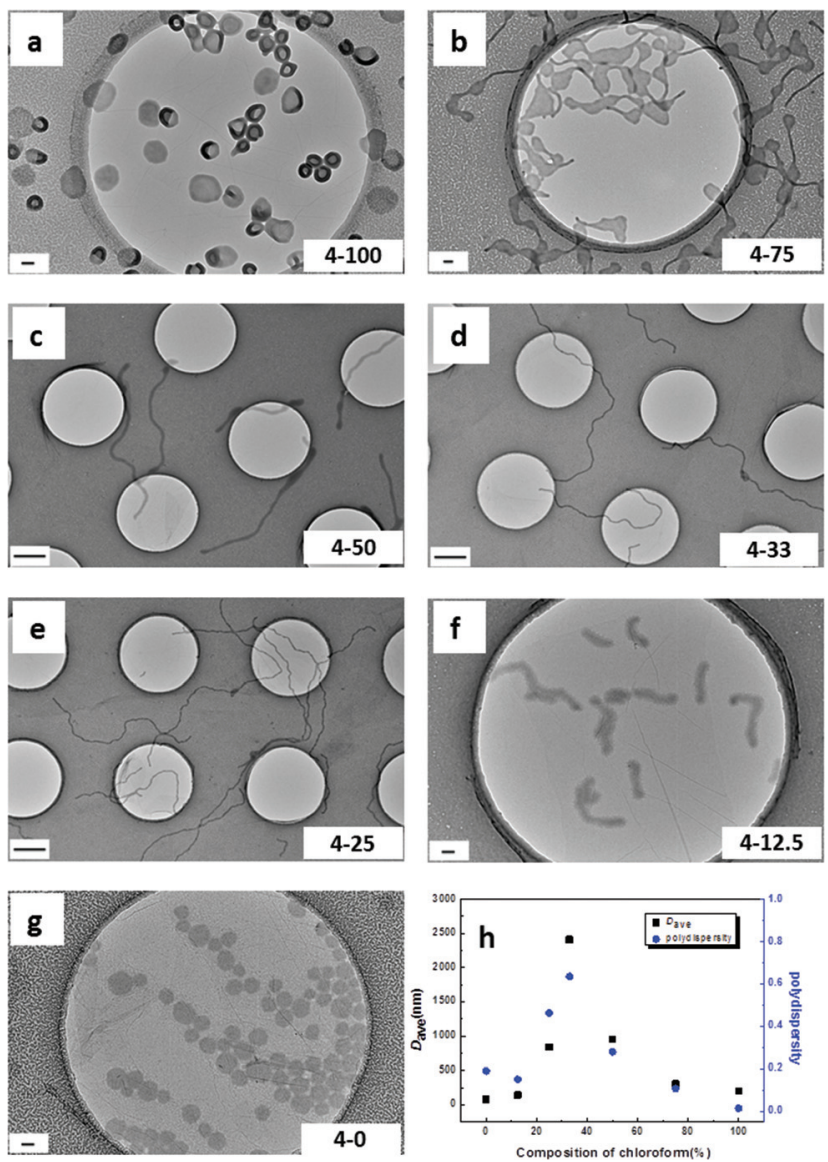

Fig. 1 Representative dry state TEM images of self-assemblies prepared by RAFT dispersion polymerization for the target polymers $\mathrm{PMMA}_{70}-b-$ $\mathrm{PTMA}_{100}, 4-\mathrm{X}$ in different solvents (from a to $\mathrm{g}$ : volume compositions of $\mathrm{CHCl}_{3}$ in $\mathrm{CHCl}_{3}$ and 1,4-dioxane mixture, $100 \%, 75 \%, 50 \%, 33 \%, 25 \%$, $12.5 \%$ and $0 \%$ ) and their corresponding size and size distributions as determined by DLS (h). Scale bar: $100 \mathrm{~nm}(1000 \mathrm{~nm}$ for c, d, and e).

(SLD) of the shell correlates well with experimental and theoretical values of both PMMA and PTMA.

When a mixture of chloroform and 1,4-dioxane (volume composition of chloroform: $75 \%$ ) was used as the solvent (Table S1 4-75, Fig. S5†), once again a bimodal polymer formed and a more complex morphology was observed. In this case lamellae with tentacles were observed by TEM analysis (Fig. 1b, 4-75). These assemblies appeared well defined by DLS analysis and had a hydrodynamic diameter of $c a .300 \mathrm{~nm}$. AFM analysis was conducted on this sample, which further confirmed the formation of lamellae with tentacles morphology. Moreover, it showed the height of the lamellae and tentacles were $c a .25$ and $35 \mathrm{~nm}$, respectively (Fig. S6†). Further decreasing the volume composition of chloroform during the polymerization to $50 \%$ led to the formation of long flexible cylinders (Table S1 4-50, Fig. S7†). From TEM analysis, the cylinders were around $5 \mu \mathrm{m}$ long (Fig. 1c, 4-50). Even longer and thinner cylinders were observed when the compositions of chloroform were $33 \%$ and $25 \%$, respectively (Fig. 1d, 4-33 and 1e, 4-25; Fig. S8 and S9†). These cylinders were more 
than $10 \mu \mathrm{m}$ in length and around $55 \mathrm{~nm}$ in width by TEM analysis. However, when the amount of chloroform used in the dispersion polymerization was dropped to $12.5 \%$, much shorter worm-like structures were obtained (Fig. 1f, 4-12.5; Fig. S10 $\dagger$ ) and the width of cylinders slightly increased to $75 \mathrm{~nm}$. DLS was also used to analyze the resultant morphologies. However, due to the highly elongated structures obtained in these systems, the sizes obtained from DLS are relative values. ${ }^{62}$

In the case of pure 1,4-dioxane as the polymerization solvent, low contrast disk-like structures with a diameter of $c a$. $100 \mathrm{~nm}$ were observed by TEM analysis (Fig. 1g, 4-0; Fig. S11†). AFM was then conducted on this sample and the heights of the structures were $c a .3-5 \mathrm{~nm}$ (Fig. S12†), which confirmed the disc-like morphology. SAXS was used to further analyze the morphology in solution (Fig. S13†). Kratky plots for spheres and cylinders were plotted with the raw data to emphasize the deviation of the scattering intensity at high- $q$ values. The sphere plot $\left(q^{2} I(q)\right.$ versus $\left.q\right)$ showed a horizontal asymptote at high $q$ values which suggests the presence of spheres. In the meantime the cylinder plot $(q I(q)$ versus $q)$ also tended to a horizontal asymptote at high- $q$ values thus confirming the presence of cylinders in solution. Such plots can suggest the assemblies have both spherical and cylindrical features. Slopes of -1 and -2 were observed in the $\log (I(q))$ versus $\log (q)$ plot, which suggests the presence of rods with a very short length. Finally different models were applied and attempts to analyze this profile with a disperse spherical uniform model, ${ }^{61}$ uniform convex lens, ${ }^{63,64}$ or uniform cylindrical models (with short length to account for a disk-like morphology ${ }^{59}$ yielded poor quality data fits. This suggests that the morphologies were not convex lenses, simple spheres or disks. Indeed, a core-shell cylindrical model with dispersity in the core radius provided the best results (Fig. S13†). ${ }^{59}$ This fit suggested that structures were formed with a core radius of ca. $9 \mathrm{~nm}$, a corona thickness of $c a .8 \mathrm{~nm}$ and a core length or depth of ca. $3 \mathrm{~nm}$, suggesting the formation of disk-like structures. Whilst this fit was the best of those examined, the quality was not as good as expected. Moreover, the large difference of dimensions obtained between the structure models utilized in the SAXS analysis and the TEM analysis suggests that the former did not reflect the entire sample. This may be due to a solvation effect or large sample dispersity in either diameter or height. Given the observations made by TEM analysis it is suggested that the dispersity is in the height of the disk rather than the diameter.

Overall, these results show that various morphologies can be accessed by varying the composition of solvent during the RAFT dispersion polymerization of TMA. However, the polymers obtained under the range of polymerization solvents were not monodisperse (Fig. S14 $\dagger$ ). Indeed bimodal chromatograms were observed by SEC analysis in each case. To eliminate the possibility that TMA monomer had undergone sidereactions during the polymerization, mixtures of TMA and CPDT were stirred at $60^{\circ} \mathrm{C}$ in chloroform under $\mathrm{N}_{2}$ atmosphere for 24 hours. Monitoring by ${ }^{1} \mathrm{H}$ NMR spectroscopy analysis, there was no obvious change observed before and after heating, which indicated that both TMA and the chain transfer agent were stable under the polymerization conditions (Fig. S15†). Therefore, it was concluded that the observed bimodal distributions of the polymers were induced by the RAFT dispersion polymerization process.

\section{Effect of TMA block length}

In addition to the effect of the solvent used for the polymerizations, the effect of varying TMA block length was also investigated using macro-CTA 2, using both chloroform and 1,4dioxane as the polymerization solvents. In chloroform the target DPs of the thymine-containing block were 20,50, and 100 and different morphologies were obtained for each polymerization in this series. When the DP of the thyminecontaining block was 20, spherical micelles were observed by TEM analysis (Fig. 2a, 5) and they were confirmed as solid spheres by SLS $\left(R_{\mathrm{g}} / R_{\mathrm{h}}=0.79\right.$, Fig. S16 $\left.\dagger\right)$. Further increasing the DP of the thymine-containing block to 50 resulted in the formation of cylinders (Fig. 2b, 6a). The length of cylinders was more than $500 \mathrm{~nm}$ by TEM analysis, however, some spherical micelles were also observed. To further determine the morphologies in solution, SANS was also conducted on sample $6 \mathbf{a}$. The Guinier-Porod model was used firstly to provide information on the shape of the scattering objects $\left(R_{\mathrm{g}}\right.$ and anisotropy). A dimension parameter of 1.32 was obtained, indicating the formation of elongated objects. However, as the minimum $q$ value is $0.004 \AA^{-1}$ and the structures are relatively big $\left(R_{\mathrm{g}}>100 \mathrm{~nm}\right)$, it is difficult to have full confidence in this fit (Fig. S18 $\dagger$ ). As a mixture of spheres and cylinders were observed by TEM analysis, a linear combination (sum model fit) of a model for spheres with some dispersity (sphere fit) ${ }^{65}$ and a model for cylinders with some dispersity (cylinder fit) was created to analyze the structures in solution (Fig. S18†).
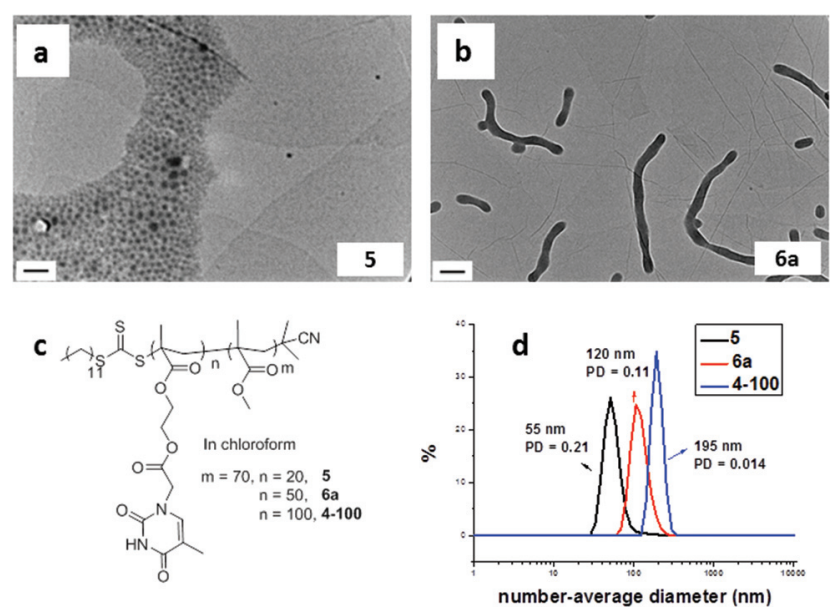

Fig. 2 (a) and (b) Representative TEM images of self-assemblies prepared by RAFT dispersion polymerization in chloroform for a target copolymer $\mathrm{PMMA}_{70}-b-\mathrm{PTMA}_{n}$, their corresponding chemical structures (c) and DLS particle size distributions (d) with increasing TMA block length. Scale bar: $100 \mathrm{~nm}$. 
This confirmed the observation by TEM analysis that both cylinders and spheres coexist in solution. As discussed above for polymer 4-100, when the DP of the thymine-containing block was increased to 100 , only vesicles were observed by TEM analysis (Fig. 1a).

Thus, with decreasing TMA block length and hence increasing weight fraction of PMMA from 54 to 32 to 19\%, as expected a morphology transition, from sphere to cylinder to vesicle was observed in the dispersion polymerization performed in chloroform. This observation is consistent with the previous observation in the literature for RAFT dispersion polymerizations, however it is interesting as the polymers in this work have much broader polydispersities which does not seem to affect the self-assembly process. ${ }^{13}$

In comparison, when 1,4-dioxane was used as the polymerization solvent, a sphere-cylinder-vesicle transition was not observed when increasing the block length of TMA from 50 to 200 (Table S1, 6b, 4-0, 7, 8; Fig. S19-S24†). Instead across the PMMA composition range (from 32 to 19 to 14 to 11 weight\%, for polymers $\mathbf{6 b}, \mathbf{4 - 0}, \mathbf{7}$, and $\mathbf{8}$, respectively) only larger micelles were observed which increased in size (from 21 to $341 \mathrm{~nm}$ ) as the DP of the PTMA block increased. The possible reason for this observation is that the nucleobase polymers have better solubility and weaker intra- and intermolecular chain interactions in 1,4-dioxane than chloroform $\left(K_{\mathrm{a}}=12\right.$ versus $20 \mathrm{M}^{-1}$ at $60^{\circ} \mathrm{C}$ ). It has been shown by van Hest, for related nucleobase systems, that solvents such as water lead to a higher than calculated lypophilic fraction, which in turns leads to the formation of spherical micelles across a broader composition window. ${ }^{38}$

\section{Effect of adenine-containing mediator}

A mediator is commonly used in nucleobase-containing chemistry for a number of reasons, including to avoid the precipitation of polymer, to protect the activity of a catalyst ${ }^{66}$ or control polymer tacticity. ${ }^{29}$ Inspired by a previous study, ${ }^{66}$ an adenine-containing mediator was used in this work to investigate its effect on the resultant self-assembly morphologies as well as the dispersity of the resultant copolymers. The adenine-containing mediator, 9-hexyladenine (Scheme 2) was

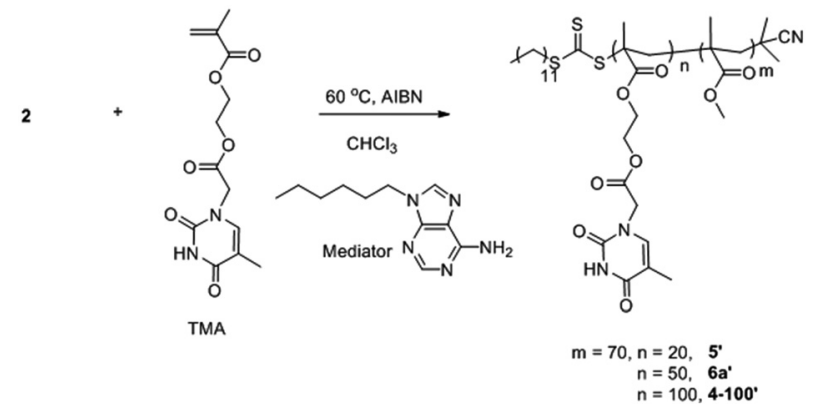

Scheme 2 Synthetic route for the thymine-containing diblock copolymers using RAFT dispersion polymerization in the presence of adeninemediator. synthesized according to a previous literature report (Scheme S1 and Fig. S25†). ${ }^{52}$

RAFT dispersion polymerization was carried out in the presence of the adenine-containing mediator (amount of TMA: mediator $=1: 1$ ) using PMMA $_{70}$ as the macro-CTA and chloroform as the solvent. The studied DPs of the thymine-containing block were 20,50, and 100 (Scheme 2, to afford polymers $\mathbf{5}^{\prime}, \mathbf{6} \mathbf{a}^{\prime}$, and $\mathbf{4 - 1 0 0}$ ' respectively). When the DP of the thyminecontaining block was 20, small spherical micelles were obtained (Fig. 3a, $5^{\prime}$ ), which was very close to the morphology obtained in the absence of the mediator (Fig. 2a, 5). Moreover, the dispersity of the resultant copolymer obtained in the presence of the mediator was much narrower compared to the copolymer obtained in the absence of mediator (Fig. 3d and $\mathrm{S} 26 \dagger)$. However, the monomer conversion was also lower (66\%) perhaps due to the improved solubility of TMA in the presence of mediator, which changes the kinetics from a dispersion polymerization to a solution polymerization.

In the case of the DP 50 TMA block, spherical micelles were observed in the presence of the mediator (Fig. 3b, 6a'), which is different from the polymerization performed, under identical conditions, without the addition of the mediator (Fig. 2b, 6a where cylinders were formed). In the presence of the adenine-containing mediator, the solubility of PTMA in chloroform increases, which decreases the apparent packing parameter of the assembly, ${ }^{67}$ therefore spherical micelles were formed instead of cylinders.

Further increasing the DP to 100 resulted in the formation of vesicles (Fig. 3c, 4-100'; Fig. S28†) similar to that observed for the polymerization without mediator (Fig. 1a, 4-100). However, in this case the vesicles possessed wrinkled membranes, which are thought to be due to the complementary interactions between the PTMA and adenine-containing mediator disrupting the assembly process. Overall, addition of
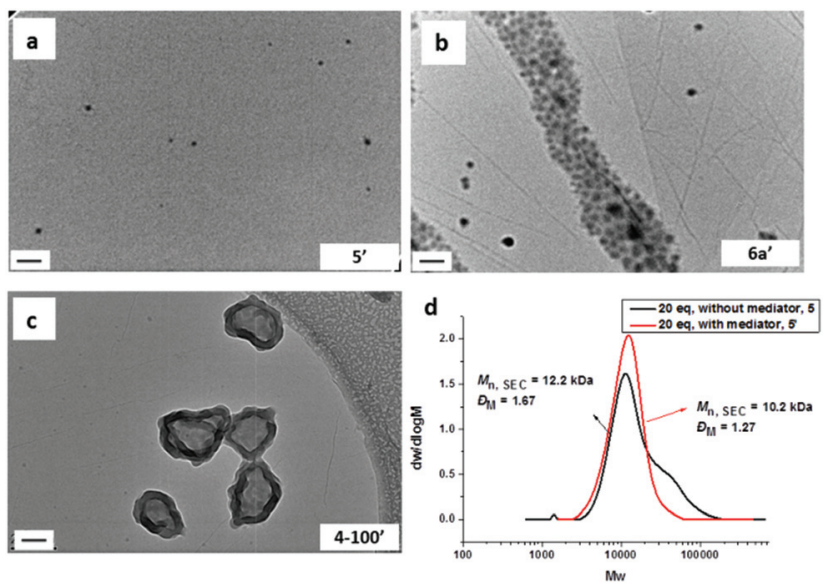

Fig. 3 Representative TEM images $(\mathrm{a}-\mathrm{c}$ ) of self-assemblies prepared by RAFT dispersion polymerization in chloroform with adenine-containing mediator for a target copolymer $\mathrm{PMMA}_{70}-b-\mathrm{PTMA}_{n}$ and SEC traces (d) of resultant copolymers obtained with or without mediator for DP 20 thymine block. Scale bar: $100 \mathrm{~nm}$. 
an adenine-containing mediator does not significantly change the observed morphology for the series of PTMA block copolymers. Moreover, a narrowing of the dispersity of the resultant copolymer is only observed for the short thymine-containing block and for the longer thymine-containing blocks, little effect on dispersity is observed.

\section{Effect of macro-CTA}

When PMMA with a DP of 70 was used as the macro-CTA above, all the polymers obtained were poorly defined and bimodal distributions were observed by SEC analysis in the majority of polymerization conditions. In order to improve the control of polymerization, a macro-CTA with a higher DP was studied as it should be better able to stabilize the growing solvent-insoluble thymine blocks. To explore this, PMMA with a DP of $220\left(\mathrm{PMMA}_{220}, 3\right)$ was used as the macro-CTA for comparison with $\mathrm{PMMA}_{70}, 2$ and the target DP of the thymine-containing block was kept constant at 50. In chloroform, spherical micelles (9a) were observed by TEM analysis when 3 was used as the macro-CTA (Fig. 4a). As expected this is different from the morphology formed when using 2 as the macro-CTA (Fig. 2b) as the longer PMMA block leads to a higher solvophilic weight fraction (59 versus $32 \%$, polymers 9a and 6). ${ }^{39}$

In contrast, when 1,4-dioxane was used as the solvent the resultant self-assembly, 9b, was not well-defined as determined by both TEM and DLS analysis (Fig. $4 \mathrm{~b}$ and S30 ${ }^{\dagger}$ ). From TEM analysis, a phase-separated pattern was observed and by DLS a broad and fluctuating distribution suggested that the resultant structures were not stable in solution. In this case it was observed that the resultant polymer, $\mathbf{9 b}$, has a significantly narrower dispersity than the related polymers prepared in chloroform (9a) or with the shorter macro-CTA (4-0) due to the improved solubility of the growing diblock in 1,4-dioxane (Fig. S30†).

In this study, nearly all the block copolymers obtained were bimodal by SEC analysis, despite this the resultant self-assemblies were surprisingly well-defined and predictable. In a dispersion polymerization, polymerization proceeds in the polymer particles as they absorb monomers from the continuous phase, ${ }^{68}$ however, in our system as the pyrimidine-pyrimidine interactions are relatively weak (compared to purinepurine interactions) and the monomer has good solubility in the polymerization solvent, we hypothesize that the monomer

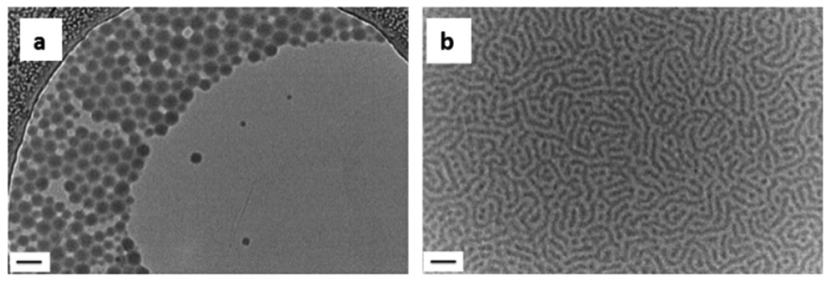

Fig. 4 Representative TEM images of self-assemblies prepared by RAFT dispersion polymerization for a target copolymer $\mathrm{PMMA}_{220}-b-\mathrm{PTMA}_{50}$ in (a) 9a, chloroform; (b) 9b, 1,4-dioxane. Scale bar: $100 \mathrm{~nm}$. absorption into the core of the particles is modest and thus the aggregates can readily establish a thermodynamic equilibrium, which leads to the formation of well-defined structures despite the broad dispersity of the constituent copolymers.

\section{Conclusions}

In conclusion, RAFT dispersion polymerizations have been utilized to polymerize thymine-containing monomers using PMMA as a macro-CTA. Effects of various factors including choice of polymerization solvent, the targeted degree of polymerization, the length of macro-CTA and the presence of an adenine-containing mediator were investigated. In general, the resultant aggregates induced by the polymerizations are well-defined despite the high dispersity of the resultant polymers. Furthermore, by changing the polymerization solvent a wide variety of morphologies could be targeted. This study demonstrates that RAFT dispersion polymerization is a facile method to prepare a variety of thymine-containing nanoobjects which may find interest in further assembly applications or recognition.

\section{Acknowledgements}

The authors thank the University of Warwick, NSF in ERC and EPSRC for funding. The SECs used in this research were obtained from Birmingham Science City, with support from Advantage West Midlands (AWM), and partly funded by the European regional development fund (ERDF). Stephen King (Rutherford Appleton Laboratory, Oxford, U.K.) is acknowledged for carrying out the SANS measurements. Dr Rebecca Williams is thanked for corrections and suggestions.

\section{Notes and references}

1 J. K. Oh, J. Polym. Sci., Part A: Polym. Chem., 2008, 46, 69837001.

2 M. F. Cunningham, Prog. Polym. Sci., 2008, 33, 365-398.

3 J. Jennings, M. Beija, J. T. Kennon, H. Willcock, R. K. O'Reilly, S. Rimmer and S. M. Howdle, Macromolecules, 2013, 46, 6843-6851.

4 V. Ladmiral, M. Semsarilar, I. Canton and S. P. Armes, J. Am. Chem. Soc., 2013, 135, 13574-13581.

5 X. W. Zhang, F. Boisson, O. Colombani, C. Chassenieux and B. Charleux, Macromolecules, 2014, 47, 51-60.

6 Y. Kitayama, Y. Kagawa, H. Minami and M. Okubo, Langmuir, 2010, 26, 7029-7034.

7 Y. Kagawa, H. Minami, M. Okubo and J. Zhou, Polymer, 2005, 46, 1045-1049.

8 J. Nicolas, A.-V. Ruzette, C. Farcet, P. Gérard, S. Magnet and B. Charleux, Polymer, 2007, 48, 7029-7040.

9 C. Farcet, B. Charleux and R. Pirri, Macromolecules, 2001, 34, 3823-3826. 
10 Y. Kitayama, K. Kishida, H. Minami and M. Okubo, J. Polym. Sci., Part A: Polym. Chem., 2012, 50, 19911996.

11 Y. Kitayama, M. Yorizane, H. Minami and M. Okubo, Polym. Chem., 2012, 3, 1394-1398.

12 J. Tonnar, P. Lacroix-Desmazes and B. Boutevin, Macromolecules, 2007, 40, 6076-6081.

13 L. A. Fielding, M. J. Derry, V. Ladmiral, J. Rosselgong, A. M. Rodrigues, L. P. D. Ratcliffe, S. Sugihara and S. P. Armes, Chem. Sci., 2013, 4, 2081-2087.

14 A. Blanazs, J. Madsen, G. Battaglia, A. J. Ryan and S. P. Armes, J. Am. Chem. Soc., 2011, 133, 16581-16587.

15 J.-T. Sun, C.-Y. Hong and C.-Y. Pan, Soft Matter, 2012, 8, $7753-7767$.

16 X. Zhang, S. p. Boissé, W. Zhang, P. Beaunier, F. D’Agosto, J. Rieger and B. Charleux, Macromolecules, 2011, 44, 41494158.

17 Z. Jia, V. A. Bobrin, N. P. Truong, M. Gillard and M. J. Monteiro, J. Am. Chem. Soc., 2014, 136, 5824-5827.

18 B. Karagoz, L. Esser, H. T. Duong, J. S. Basuki, C. Boyer and T. P. Davis, Polym. Chem., 2014, 5, 350-355.

19 N. J. Warren, O. O. Mykhaylyk, A. J. Ryan, M. Williams, T. Doussineau, P. Dugourd, R. Antoine, G. Portale and S. P. Armes, J. Am. Chem. Soc., 2015, 137, 1929-1937.

20 M. Semsarilar, N. J. W. Penfold, E. R. Jones and S. P. Armes, Polym. Chem., 2015, 6, 1751-1757.

21 B. Charleux, G. Delaittre, J. Rieger and F. D'Agosto, Macromolecules, 2012, 45, 6753-6765.

22 J. Rieger, Macromol. Rapid Commun., 2015, DOI: 10.1002/ marc. 201500028.

23 C. A. Figg, A. Simula, K. A. Gebre, B. S. Tucker, D. M. Haddleton and B. S. Sumerlin, Chem. Sci., 2015, 6, 1230-1236.

24 M. J. Derry, L. A. Fielding and S. P. Armes, Polym. Chem., 2015, 6, 3054-3062.

25 S. Sugihara, S. P. Armes, A. Blanazs and A. L. Lewis, Soft Matter, 2011, 7, 10787-10793.

26 P. Chambon, A. Blanazs, G. Battaglia and S. P. Armes, Macromolecules, 2012, 45, 5081-5090.

27 W.-J. Zhang, C.-Y. Hong and C.-Y. Pan, Macromolecules, 2014, 47, 1664-1671.

28 Y. Kang, A. Pitto-Barry, H. Willcock, W.-D. Quan, N. Kirby, A. M. Sanchez and R. K. O'Reilly, Polym. Chem., 2015, 6, 106-107.

29 Y. Tao, K. Satoh and M. Kamigaito, Macromol. Rapid Commun., 2011, 32, 226-232.

30 C. R. South and M. Weck, Macromolecules, 2007, 40, 13861394.

31 R. McHale, J. P. Patterson, P. B. Zetterlund and R. K. O'Reilly, Nat. Chem., 2012, 4, 491-497.

32 P. K. Lo and H. F. Sleiman, J. Am. Chem. Soc., 2009, 131, 4182-4183.

33 Y. Tao, Y. Yang, D. Shi, M. Chen, C. Yang and X. Liu, Polymer, 2012, 53, 1551-1557.

34 R. J. Thibault, P. J. Hotchkiss, M. Gray and V. M. Rotello, J. Am. Chem. Soc., 2003, 125, 11249-11252.
35 F. Ilhan, T. H. Galow, M. Gray, G. Clavier and V. M. Rotello, J. Am. Chem. Soc., 2000, 122, 5895-5896.

36 A. K. Boal, F. Ilhan, J. E. DeRouchey, T. Thurn-Albrecht, T. P. Russell and V. M. Rotello, Nature, 2000, 404, 746748.

37 L. P. Stubbs and M. Weck, Chem. - Eur. J., 2003, 9, 992999.

38 H. J. Spijker, A. J. Dirks and J. C. M. van Hest, J. Polym. Sci., Part A: Polym. Chem., 2006, 44, 4242-4250.

39 A. Blanazs, S. P. Armes and A. J. Ryan, Macromol. Rapid Commun., 2009, 30, 267-277.

40 A. L. Schmitt, M. H. Repollet-Pedrosa and M. K. Mahanthappa, ACS Macro Lett., 2012, 1, 300-304.

41 P. Lim Soo and A. Eisenberg, J. Polym. Sci., Part B: Polym. Phys., 2004, 42, 923-938.

42 X. Wang, J. L. Davis, J. P. Hinestrosa, J. W. Mays and S. M. Kilbey, Macromolecules, 2014, 47, 7138-7150.

43 O. Terreau, L. Luo and A. Eisenberg, Langmuir, 2003, 19, 5601-5607.

44 W. Batsberg, S. Ndoni, C. Trandum and S. Hvidt, Macromolecules, 2004, 37, 2965-2971.

45 S. Hvidt, C. Trandum and W. Batsberg, J. Colloid Interface Sci., 2002, 250, 243-250.

46 P. Linse, Macromolecules, 1994, 27, 6404-6417.

47 D. J. Adams, M. F. Butler and A. C. Weaver, Langmuir, 2006, 22, 4534-4540.

48 L. Chen, T. Ci, T. Li, L. Yu and J. Ding, Macromolecules, 2014, 47, 5895-5903.

49 S. Jain and F. S. Bates, Macromolecules, 2004, 37, 15111523.

50 Y. K. Chong, G. Moad, E. Rizzardo and S. H. Thang, Macromolecules, 2007, 40, 4446-4455.

51 Y. Kang, A. Lu, A. Ellington, M. C. Jewett and R. K. O'Reilly, ACS Macro Lett., 2013, 2, 581-586.

52 Z. Wang, Y. Yu, D. Zhang and D. Zhu, Chin. Sci. Bull., 2006, 51, 1947-1954.

53 J. P. Patterson, A. M. Sanchez, N. Petzetakis, T. P. Smart, T. H. Epps III, I. Portman, N. R. Wilson and R. K. O'Reilly, Soft Matter, 2012, 8, 3322-3328.

54 T. M. Reed and T. E. Taylor, J. Phys. Chem., 1959, 63, 58-67.

55 S. Kline, J. Appl. Crystallogr., 2006, 39, 895-900.

56 N. S. L. D. Calculator, http://www.ncnr.nist.gov/resources/ sldcalc.html.

57 H. Peng, D. Chen and M. Jiang, J. Phys. Chem. B, 2003, 107, 12461-12464.

58 J. P. Patterson, M. P. Robin, C. Chassenieux, O. Colombani and R. K. O'Reilly, Chem. Soc. Rev., 2014, 43, 2412-2425.

59 A. Guinier and G. Fournet, Small-angle scattering of X-rays, Wiley, 1955.

60 S. Hocine, A. Brulet, L. Jia, J. Yang, A. Di Cicco, L. Bouteiller and M.-H. Li, Soft Matter, 2011, 7, 26132623.

61 J. B. Hayter, Physics of amphiphiles-micelles, vesicles, and microemulsions, Varenna on Lake Como, Villa Monastero, 1983. 
62 N. Petzetakis, D. Walker, A. P. Dove and R. K. O'Reilly, Soft Matter, 2012, 8, 7408-7414.

63 H. Kaya, J. Appl. Crystallogr., 2004, 37, 223-230.

64 H. Kaya and N.-R. De Souza, J. Appl. Crystallogr., 2004, 37, 508-509.

65 P. Bartlett and R. H. Ottewill, J. Chem. Phys., 1992, 96, 3306-3318.
66 J. Romulus and M. Weck, Macromol. Rapid Commun., 2013, 34, 1518-1523.

67 J. Rodríguez-Hernández, F. Chécot, Y. Gnanou and S. Lecommandoux, Prog. Polym. Sci., 2005, 30, 691724.

68 G. Odian, Principles of Polymerization, John Wiley \& Sons, Inc., Hoboken, 4th edn, 2004. 